\title{
Evolution of the Neobladder: A Critical Review of Open and Intracorporeal
}

\section{Neobladder Reconstruction Techniques}

Wei Shen Tan ${ }^{1,2}$, Benjamin W Lamb², John D Kelly ${ }^{1,2}$

1. Division of Surgery \& Interventional Science, University College London, London, UK

2. Department of Urology, University College London Hospital, London, UK

Running title:

\section{Evolution of Neobladder Reconstruction}

Corresponding author:

Wei Shen Tan

Division of Surgery \& Interventional Science,

University College London,

74 Huntley Street,

London, WC1E 6AU.

Email: tanweishen@hotmail.com

Tel: +44(0)7725953115

Fax:: +44(0)20 76796470

Word count: $\mathbf{3 8 5 3}$ 


\section{Abstract}

Orthotopic neobladder is an attractive alternative to the ileal coundit following radical cystectomy. Robotic cystectomy is gaining popularity although the uptake of neobladder reconstruction is low, with the majority of cases being constructed extracorporeally via a mini-laparotomy. Minimally invasive cystectomy using the robotic platform facilitates intracoporeal neobladder reconstruction and several techniques have been described. In this review we discuss issues relating to patient selection, and describe existing techniques of open surgical neobladder reconstruction, and their evolution to suit an intracorporeal approach. A Medline search for publication from Jan 1970 to Sept 2015 with the following keyword search criteria was performed: radical cystectomy, robotic cystectomy, intracorporeal, neobladder, orthotopic bladder reconstruction, surgical technique, patient selection and ureteric-ileal anastomosis.

\section{Key words}

Bladder cancer

Bladder reconstruction

Neobladder

Radical cystectomy

Urinary diversion 


\section{Introduction}

Although the ileal coundit diversion is the most common reconstruction after radical cystectomy, studies have shown that in the suitable patient, an orthotopic neobladder may offer better quality of life by maintaining patient body image and facilitating near normal voiding (1). The development of robotic assisted radical cystectomy (RARC) and intracorporeal orthotopic neobladder represents an evolution of minimal access surgery which was previously not possible using conventional laparoscopic techniques. Although RARC was first reported over a decade ago, neobladder reconstruction following robotic cystectomy has been achieved in the main by conversion to open mini-laparotomy. A recent randomised controlled trail between RARC with extracorporeal urinary diversion and open cystectomy reported that early complications and length of stay between the two treatment mordality are similar although blood loss was significantly lower and operating time was longer in RARC patients(2). However, arguably, the benefits of a minimally invasive approach can only be achieved by completion of urinary neobladder reconstruction with an intracorporeal approach (3). Contemporary series suggest that overall, intracorporeal neobladder is performed in less than $10 \%$ of cases although in a number of institutions, it has become the standard approach (3, 4). Factors contributing to the low uptake of intracorporeal reconstruction may include the technical complexity, prolonged operative time, and the requirement for steep Trendelenburg position. Several intracorporeal neobladder techniques have been described which replicate contemporary open techniques (5-7). However, simplifying the procedure remains a challenge and long term functional follow-up is essential for any variation over standard techniques. 
This review will focus on established techniques of open neobladder reconstruction, and how they have been adapted to the developing field of robotic intracorporeal reconstructive surgery. The key elements of case selection and the optimisation of functional outcomes will be discussed, as well as opportunities for future research and development.

\section{Search criteria}

A literature search confined to publications in English from January 1970 to September 2015 was performed using the Medline electronic database. Keyword search criteria include: radical cystectomy, robotic cystectomy, intracorporeal, neobladder, orthotopic bladder reconstruction, surgical technique, patient selection and ureteric-ileal anastomosis. An additional manual search of references of relevant published articles was also performed. Only studies reporting established open reconstruction techniques and intracorporeal RARC techniques reporting on at least 10 patients were included.

\section{Patient selection for open and robotic neobladder reconstruction}

\section{Oncological consideration}

The factors that must be considered when selecting patients for both open and robotic neobladder reconstruction are similar, with the added fact that in robotic cases intra-peritoneal adhesions from previous abdominal surgery can make access to the peritoneal cavity difficult. The risk of tumour recurrence in the remaining lower genito-urinary tract should be given careful consideration when selecting patients for 
bladder reconstruction. The presence of tumour in the prostatic urethra is a risk factor for urethral recurrence especially if present within the prostatic stroma (8). Disease at the bladder neck, multifocal tumour and carcinoma in situ (cis) are not contraindications for neobladder reconstruction in men (9). Ideally, resection biopsy of the prostatic urethra is performed prior to radical cystectomy and neobladder reconstruction (9). Alternatively, a urethral frozen section can be performed to confirm the absence of tumour during radical cystectomy, although the presence of cis may be missed in up to $33.9 \%$ of cases (10). Female patients with bladder neck and vaginal wall involvement have a $53 \%$ and a $60 \%$ risk of urethral and local recurrence respectively $(11,12)$. This group of patients should not be considered for orthotopic neobladder reconstruction, although heterotopic reconstruction with Mitrofanoff diversion may be an alternative.

It remains controversial whether the extent of disease in the pelvis should be a consideration when selecting type of urinary diversion. The Pasadena Consensus Panel specify that the extent of tumour should be a consideration, whilst the 2012 International Consultation on Bladder Cancer suggested that the extent of pelvic disease should not preclude neobladder reconstruction $(9,13)$. Based on the evidence available, it is the authors' view that the decision to offer neobladder to patients with locally advanced disease should take $T$ stage and nodal status into account. The 5 year overall survival (OS) and cancer specific survival (CSS) for patients with $>$ T2N0 disease is $53 \%$ and $62 \%$ respectively, and for patients with node positive disease, OS and CSS drops to $32 \%$ and $40 \%$ respectively (14). Although, neobladder reconstruction is described in cases of advanced stage and nodal disease, the decision to offer neobladder reconstruction must also balance the time for the neobladder to mature into an effective reservoir against the time to 
recurrence. The mean time to disease recurrence is 10 months and the majority of deaths will be within 2 years $(14,15)$.

Erectile dysfunction is common in men after conventional cystoprostatectomy, even if nerve sparing techniques is employed (16). Prostate sparing surgery, or prostate capsule sparing surgery might offer an option for preservation of potency with case series reporting day time and night time continence rates of $96 \%$ and $82 \%$ respectively as well as preservation of erectile function in $90 \%$ of cases (17). In addition to other standard investigations, it is recommended that prior to undergoing prostate sparing cystectomy such men have a PSA measurement and transrectal ultrasound guided prostate biopsies to exclude prostate cancer (17). However, caution is advised when considering this technique in men with benign prostatic hyperplasia due to the potential risk of high pressure chronic retention, which may leading to renal impairment if intermittent catheterisation is not performed (7). In females with $\leq \mathrm{pT} 2$ disease located away from vagina and uterus pelvic organ preservation may enhance functional outcomes without compromising oncological safety (18) .

\section{Patient factors}

Compromised renal function is a contraindication for open or robotic neobladder reconstruction. It is well known that prolonged contact of urine with the interposed bowel segment leads to increased absorption of ammonia, which in turn results in a net positive balance of hydrogen ions. Patients with poor renal reserve are unable to excrete the increased load of hydrogen ions, which results in hyperchloremic metabolic acidosis. Clinical features of dehydration, lethargy, nausea, vomiting and 
seizures can develop if the acidosis goes untreated (19). Although, there is no absolute cut off, it is generally accepted that a glomerular filtration rate (GFR) of $50 \mathrm{ml} / \mathrm{min}$ is a threshold below which neobladder reconstruction should not be performed (20). Similarly, hepatic impairment may lead to hyperammonemia due to an inability of the liver to metabolise the increased levels of ammonium that are absorbed by the neobladder (21). This can result in encephalopathy and for that reason, hepatic impairment is also a contraindication.

Other contraindications include inflammatory bowel disease, especially Crohn's disease, although patients with ulcerative colitis may be considered for an ileal neobladder. The option for neobladder reconstruction in cases with pure ulcerative colitis may be in conflict with the requirement for small bowel ileal-anal pouch formation following total colectomy resection.

Relative contraindications include previous pelvic radiation, previous bowel resection, urethral stricture, poor external urethral sphincter function and previous radical prostatectomy. Patients with poor external sphincter function can be considered for artificial urinary sphincter insertion if they have a strong preference for neobladder reconstruction. Increasing age is not a contraindication to neobladder reconstruction but a careful assessment of comorbidity and physical and cognitive status is important (22). It is essential that patients are engaged with the care program required to manage their neobladder, which includes intermittent selfcatheterisation. Failure to adequately empty the neobladder may result in rupture, which is why cognitive impairment, insufficient physical dexterity and unwillingness to perform self-intermittent catheterisation are all relative contraindications. 


\section{Intestinal segment for bladder reconstruction}

The ideal bladder substitution should maintain a low pressure during the filling phase, have high compliance with good continence. The reservoir should empty on voiding, be impermeable to solutes and protective of the upper urinary tract. Unfortunately, at present there is no bladder substitute that is able to fulfil all the above requirements.

The most popular intestinal segment used for neobladder reconstruction is llium, followed by ileal-caecal and colon. The use of stomach and jejunum have been reported, but are considered technically impractical options. A sufficient length of intestinal segment must first be detubularized in order prevent peristaltic contractions and allow a large volume $(500 \mathrm{ml})$, low pressure reservoir. Urodynamic assessment comparing the pouch pressures of different bowel segments indicates that ilium is more compliant and less contractile, resulting in improved continence rates than either colon or stomach (23). Table 1 lists the different intestinal segments summarises their advantages and disadvantages.

\section{Refluxing or Non-refluxing ureteric-ileal anastomosis?}

Table 2 presents a variety of reconstruction techniques that have been developed with the aim of preserving renal function by minimising ureteric reflux and anastomotic stricture. Anti-reflux techniques attempt to replicate the competency of the native ureteric implantation and prevent the reflux of high levels of bacteria that are present within the neobladder, and which may lead to ascending pyelonephritis and renal impairment $(24,25)$. Urodynamic studies have reported neobladder pressures of up to $150 \mathrm{cmH}_{2} \mathrm{O}$ during voiding in patients with the anti-reflux Kock 
neobladder, which over the long term in the absence of an anti-reflux mechanism would be detrimental to renal reserve (26). However, high voiding pressures have not been confirmed by others authors, and voiding scintigraphy studies in patients with freely refluxing uretero-ileal anastomosis have confirmed the absence of ureteric reflux (27).

The initial Kock neobladder, $\mathrm{T}$ pouch and Le Duc anastomosis reported stricture rates as high as 10.4-29\% (28-30). Moreover, data from a randomised trial report that patients with an anti-reflux anastomosis had a significantly higher stricture rate compared to refluxing anastomosis (31). A another randomised trial by Skinner and colleagues showed that there was no difference in three years postoperative renal function or risk of urinary tract infection between the T pouch and Studer neobladder although $\mathrm{T}$ pouch patients had a much higher re-intervention rate due to uretero-ileal stricture and afferent limb stenosis (32). It is well established that undiagnosed uretero-ileal strictures will result in a decline in renal function and early intervention in patients receiving the T pouch may have prevented any significant decline. However, not all anti-refluxing anastomosis report high stricture rates. The Abol-Enein \& Ghoneim pouch and the I pouch have a stricture rate of between $2.1-3.8 \%(33,34)$. However, given that there is no benefit in performing anti-refluxing anastomosis, freely refluxing anastomosis has become the anastomosis of choice.

An alternative to anti-reflux implantation is a long afferent limb, which is postulated to be advantageous if a refluxing uretero-ileal anastomosis is performed (35). However, techniques with direct uretero-ileal anastomosis to neobladder have not been shown to have an adverse effect on upper tracts and renal function $(36,37)$. It is reasonable to postulate that the most important factor in preserving upper tract integrity appears to be the low pressure afforded by the formation of a large volume 
pouch using an adequate length of detubularised and folded bowel (37). Long term outcomes with particular reference to renal preservation have not supported the requirement for anti-reflux ureteric implantation in open surgery, and consequently have not been adopted for robotic surgery.

Refluxing uretero-ileal anastomosis is typically performed by either a Bricker or Wallace anastomosis. Type of anastomosis performed is dependent on surgeon preference. Proponents of the Wallace technique perceive that it has a lower stricture rate compared to the Bricker anastomosis although there is a higher risk of bilateral ureteric obstruction in the event of a stricture, tumour recurrence or renal calculi. A recent meta-analysis on retrospective cohort series report that there is no difference in stricture rates between Bricker and Wallace anastomosis (38).

\section{Open neobladder reconstruction}

The two most popular neobladder reconstruction techniques include the Studer ileal afferent limb neobladder and the Hautmann ' $W$ ' neobladder. Other techniques include the Kock ileal neobladder, T- pouch, Padua ileal neobladder and the AbolEnein and Ghoneim's 'W' neobladder. All neobladders adhere to Laplace's law and are spherical in configuration; cross folded and have a good capacity to promote low intraluminal pressure. Functional outcomes of these techniques are summarised in Table 3.

\section{Studer neobladder}


The Studer neobladder is popular due to its relatively simple construction. Excellent long term continence rates are reported and the afferent limb can be tailored for cases with short ureters (35). A segment of the terminal ilium approximately $55 \mathrm{~cm}$ in length, $25 \mathrm{~cm}$ from the ileo-caecal valve is used to construct the neobladder. $40 \mathrm{~cm}$ of the selected segment is detubularized and folded into a $U$ configuration, leaving a proximal $15 \mathrm{~cm}$ afferent limb segment into which the ureters are implanted using Bricker or Wallace technique. It has been argued that this afferent limb can reduce the risk of urinary reflux secondary to intra-abdominal pressure (39).

\section{Hautmann neobladder}

The Hautmann neobladder involves the formation of a large capacity, 'W' configuration spherical reservoir using $70 \mathrm{~cm}$ of terminal ilium incised at its antimesenteric border and constructed with a running absorbable suture (36). Refluxing ureteric anastomoses are performed. The 'W' configuration results in complete detubularization of bowel which promotes excellent continence rates, but can increase the risk of late urinary retention due to its large capacity $(40,41)$. This is particularly more common in women patients where the risk of urinary retention is up

to $50 \%$ at 5 years compared to $11 \%$ in men (42). Hence, women should be counselled on the high possibility of intermittent catheterisation use. Short ureters require a modification of the original $W$ neobladder leaving one end of the ileal segment longer to facilitate a tension free uretero-ileal anastomosis. 


\section{Kock ileal reservoir / T pouch neobladder}

The Kock ileal neobladder uses approximately $60 \mathrm{~cm}$ of ilium, from which two $22 \mathrm{~cm}$ segments are placed in a ' $U$ ' configuration, with a proximal $17 \mathrm{~cm}$ intussuscepted nipple valve (43). This anti-reflux valve is fashioned by intussuscepting the afferent limb which is fixed by two staples. Long term follow-up has revealed that a significant number of patients present with bilateral hydronephrosis or chronic renal failure secondary to afferent nipple stenosis, thought to be due to an impaired blood supply, or stone formation on the staples (28). The Kock technique has been replaced by the T-pouch ileal neobladder that was developed by Stein et al (29). The T- pouch technique uses the same $U$ configuration as the Kock except the intussuscepted segment is replaced with a tapered afferent ileal segment in which the mesenteric segments (Windows of Denver) are opened and held in position by small Penrose drains. The afferent portion is then anchored to the two ileal ' $U$ ' shaped segments and the two ileal flaps fold over the afferent segment to create an anti-reflux mechanism. As there is little evidence for the requirement for an anti-reflux mechanism, coupled with increased technical demands, it is likely that neither the Koch or 'T' pouch will receive global adoption.

\section{Padua ileal neobladder}

First described in 1987, the 'Vescica lleale Padovana' is a technique that only utilises $40 \mathrm{~cm}$ of ilium (44). Urodynamics studies report good functional outcomes and ileal tone is maintained preventing over-distension which results in satisfactory bladder emptying (45). The ilial segment is isolated and incised along the anti-mesenteric border and a funnel created inferiorly to promote drainage into a tension free 
urethrointestinal anastomosis. The proximal loop of the detubularized ilium is folded in a reverse ' $S$ ' configuration and sutured on its sides to create an ileal cup. The ureteroileal anastomosis is performed using a serous-lined extramural ureteral replantation as described by Abol-Eneim and Ghoneim (see below) (34). The ureteric end is spatulated for the anastomosis, which is then stented. The anterior aspect of the neobladder is then folded downwards and sutured with a running absorbable suture.

Although using a shorter segment of ilium is attractive as it reduces the risk of metabolic and gastrointestinal complications such as diarrhoea and vitamin B12 deficiency, this has to be balanced against the potential risk of higher storage pressure and impaired continence due to a smaller bladder capacity.

Zhang et al. described a similar reconstruction using $40 \mathrm{~cm}$ of ileum described as the ' $N$ ' reservoir (46). The main difference is the absence of the extramural reimplantation in favour of a direct uretero-reservoir anastomosis, which in a recent report of urodynamic studies was associated with low voiding pressures.

\section{Abol-Enein and Ghoneim's 'W' neobladder}

Abol-Enein and Ghoneim described a 'W' shaped ileal neobladder with anti-reflux properties comprising of a serous lined extramural tunnel $(34,47) .40 \mathrm{~cm}$ of ilium is isolated and arranged into a 'W' configuration. The ureters are positioned in the medial flap troughs and the mucosa is closed in front to form a serous-lined antireflux intestinal tunnel. Long term outcomes show that reflux was observed in $3 \%$ of patients, and the rate of uretero-ileal anastomotic structure is low (34). However, this ureteroileal anastomotic technique requires ureters of considerable length is not 
suitable for grossly dilated ureters. Further, creating an extramural tunnel using ilium can be challenging compared to colonic neobladders due to a less well defined muscularis externus layer.

\section{$\underline{\text { Robotic assisted intracorporeal neobladder reconstruction }}$}

Over more than two decades, numerous techniques for the construction of continent urinary reservoirs have been described for open radical cystectomy. Some of these techniques have been modified for robotic surgery with surgeons seeking to replicate principles that have proven successful in open surgery. The robotic intracorporeal neobladder continues to evolve, and efforts to simplify the technique and reduce the operative time will continue to be necessary to command widespread adoption.

To date, no techniques for bladder reconstruction using colonic segments in robotic procedures have been described (Table 4) $(5-7,48)$. All techniques describe a refluxing uretero-ileal anastomosis. Jonsson et al. describes the initial step of urethro-ileal anastomosis having identified a section of $60 \mathrm{~cm}$ of ileum which will spare at least $12 \mathrm{~cm}$ of terminal ileum (Figure 1D) (49). The lack of tactile feedback mandates careful manipulation of intestine to the deep pelvis in a steep Trendelenburg position. Goh and colleagues describe the formation of the urethroileal anastomosis after isolation and detubularization of the bowel segment (Figure 1C) (6) and Pruthi and colleagues described complete pouch formation followed by anastomosis but in a limited series of cases (Figure 1B) (48). In our experience, manoeuvring the intestinal segment to urethra and completing the urethro-ileal anastomosis can be demanding, especially in obese patients. Accordingly our 
preference is to complete the urethra-ileal anastomosis at an early stage before resecting the bowel segment (7).

Goh and colleagues (Figure 1C) and Jonsson and colleagues (Figure 1D) describe a robotic modification of the Studer reservoir using $60 \mathrm{~cm}$ of ilium $(6,49)$. At our institute, we performed a detubularized cross folding Pyramid neobladder without an afferent limb using $50 \mathrm{~cm}$ of ilium (Figure1A) (7).

Although described as a small series, Pruthi and colleagues (Figure 1B) describes a 'U' shaped neobladder which does not involve cross-folding (48). The lack of crossfolding may result in a higher intraluminal pressure which may compromise renal function. However, no long term follow-up data has been reported regarding renal function preservation. This neobladder is constructed using a stapling device rather than absorbable sutures and traditionally most surgeons are reluctant to use staples due to the risk of calculi formation. However in practice, neobladder calculi have not been noted as a problem with the use of modern stapling devices. $(50,51)$. While long term follow-up is needed, the relatively simple and fast technique of intracoporeal stapling using contemporary devices remains attractive.

All intracorporeal neobladders that have been described in the literature incorporate a $3 \mathrm{~cm}$ spatulated uretero-ileal anastomosis without anti-reflux mechanism either using the Bricker or Wallace technique. Long term follow up data on renal function and stricture formation is available for similar techniques in open surgery, which is widely accepted to translate to outcomes for intracorporeal neobladder. The Pyramid neobladder incorporates a direct ureter to neobladder anastomosis as described by others, with the option of forming a long afferent loop that can be used in patients with short ureters. Urodynamic studies performed in patients with a similar 
neobladder configuration constructed using open techniques confirms low neobladder pressures at 12 months (37). The advantage of this simplified intracorporeal reconstruction technique is shorter operative time and reduced duration of steep Trendelenburg.

Long term follow-up data for preservation of renal function and functional outcomes are limited given the novelty of intracorporeal neobladder reconstruction. Techniques described by Goh and colleagues and Jonsson and colleagues attempt to replicate the Studer neobladder while the Pyramid neobladder is an evolution of a previously described open ileal neobladder technique (37). Hence, intracorporeal reconstruction should adhere to principles and open reconstruction techniques which have stood the test of time.

\section{Steps to overcome difficulties in intracorporeal neobladder reconstruction}

One of the most challenging parts of intracorporeal neobladder reconstruction is the urethra-ileal anastomosis. A tension free anastomosis is essential to prevent anastomosis and stricture. Careful dissection of the junction of the prostatic apex and external sphincter after dorsal venous complex ligation allows preservation of maximum membranous urethral length which has been shown to improve continence in radical prostatectomy (52). Prior to bowel segment isolation, careful identification of the segment of ileal for neobladder reconstruction with the longest mesentery is essential to ensure that the ilium loop can reach the urethra. If necessary, multiple transverse mesenteric serosal incisions can be made to achieve additional length in the order of several centimetres but care should be taken to avoid damaging mesenteric vessels. Manoeuvres using rubber sloops can facilitate traction on the 
bowel segment. Suturing using barbed sutures such as V-Loc can minimise the risk of urinary leak by preventing slippage and allows the appropriate tension to be applied (53).

\section{Future prespectives}

The benefits of RARC remain controversial. The recently published Pasadena consensus panel systemic review concluded that RARC was associated with significantly lower blood loss and transfusion rates but higher cost compared to open cystectomy although there was no difference between postoperative mortality and morbidity (54). This is echoed by a randomised control trial of extracorporeal RARC versus open cystectomy by Bochner and colleagues (55). However, none of the patients in this study had intracorporeal division and the need for a mini-laparotomy for urinary diversion in the RARC arm may have negated any advantages of minimal invasive surgery. Another randomised trial with the aim of recruiting 320 patients comparing open RC and RARC with extracorporeal diversion is under way (56). However, arguably, the greatest benefit for patients will be those with intracorporeal urinary diversion although currently, there is a void of evidence to support this.

\section{Conclusions}

Although, many techniques and different intestinal segments have been tried and tested, the ileal neobladder appears to be technically feasible, whilst offering reliable functional outcomes. The shift towards robotic intracorporeal neobladder has led to the development of simplified techniques combined with a desire to preserve functional outcomes and prevent complications. The advent of dissolvable bowel 
staplers may shorten operating time but it is unproven if it reduces the stone formation rates compared to conventional staplers.

It is now accepted that short and intermediate term complications and oncological outcomes in extracorporeal RARC are at least equivocal to open cystectomy (54). However, there is still limited data on long term oncological outcomes and complications relating to urinary diversion as well as the perceived advantages of intracorporeal RARC. Further studies will be needed to address these issues.

\section{Conflict of interest}

The authors declare that there are no conflicts of interest regarding the publication of this paper.

\section{Acknowledgements}

We are grateful to the UCLH Biomedical Research Centre for funding our work. 


\section{References}

1. Dutta SC, Chang SS, Coffey CS, Smith JA, Jack G, Cookson MS. Health related quality of life assessment after radical cystectomy: comparison of ileal conduit with continent orthotopic neobladder. The Journal of urology. 2002;168(1):164-7.

2. Bochner BH, Dalbagni G, Sjoberg DD, Silberstein J, Paz GEK, Donat SM, et al. Comparing open radical cystectomy and robot-assisted laparoscopic radical cystectomy: a randomized clinical trial. Eur Urol. 2015;67(6):1042-50.

3. Ahmed K, Khan SA, Hayn MH, Agarwal PK, Badani KK, Balbay MD, et al. Analysis of intracorporeal compared with extracorporeal urinary diversion after robot-assisted radical cystectomy: results from the International Robotic Cystectomy Consortium. Eur Urol. 2014;65(2):340-7. Epub 2013/11/05.

4. Parra $\mathrm{RO}$, Andrus $\mathrm{CH}$, Jones JP, Boullier JA. Laparoscopic cystectomy: initial report on a new treatment for the retained bladder. J Urol. 1992;148(4):1140-4. Epub 1992/10/01.

5. Collins JW, Tyritzis S, Nyberg T, Schumacher M, Laurin O, Khazaeli D, et al. Robot-assisted radical cystectomy: description of an evolved approach to radical cystectomy. Eur Urol. 2013;64(4):654-63.

6. Goh AC, Gill IS, Lee DJ, de Castro Abreu AL, Fairey AS, Leslie S, et al. Robotic intracorporeal orthotopic ileal neobladder: replicating open surgical principles. Eur Urol. 2012;62(5):891-901. Epub 2012/08/28.

7. Tan WS, Sridhar A, Goldstraw M, Zacharakis E, Nathan S, Hines J, et al. Robot Assisted Intracorporeal Pyramid Neo-bladder. BJU Int. 2015. Epub 2015/06/03.

8. Boorjian SA, Kim SP, Weight CJ, Cheville JC, Thapa P, Frank I. Risk factors and outcomes of urethral recurrence following radical cystectomy. Eur Urol. 2011;60(6):1266-72.

9. Hautmann RE, Abol-Enein H, Davidsson T, Gudjonsson S, Hautmann SH, Holm HV, et al. ICUD-EAU International Consultation on Bladder Cancer 2012: Urinary diversion. Eur Urol. 2013;63(1):67-80.

10. Gordetsky J, Bivalacqua T, Schoenberg M, Epstein Jl. Ureteral and urethral frozen sections during radical cystectomy or cystoprostatectomy: an analysis of denudation and atypia. Urology. 2014;84(3):619-23.

11. Stein JP, Cote RJ, Freeman JA, Esrig D, Elmajian DA, Groshen S, et al. Indications for lower urinary tract reconstruction in women after cystectomy for bladder cancer: a pathological review of female cystectomy specimens. J Urol. 1995;154(4):1329-33. Epub 1995/10/01.

12. Maralani S, Wood DP, Jr., Grignon D, Banerjee M, Sakr W, Pontes JE. Incidence of urethral involvement in female bladder cancer: an anatomic pathologic study. Urology. 1997;50(4):537-41. Epub 1997/10/24 21:29.

13. Wilson TG, Guru K, Rosen RC, Wiklund P, Annerstedt M, Bochner BH, et al. Best practices in robot-assisted radical cystectomy and urinary reconstruction: recommendations of the Pasadena Consensus Panel. Eur Urol. 2015;67(3):363-75. Epub 2015/01/15.

14. Yafi FA, Aprikian AG, Chin JL, Fradet Y, Izawa J, Estey E, et al. Contemporary outcomes of 2287 patients with bladder cancer who were treated with radical cystectomy: a Canadian multicentre experience. BJU Int. 2011;108(4):539-45.

15. Yossepowitch O, Dalbagni G, Golijanin D, Donat SM, Bochner BH, Herr HW, et al. Orthotopic urinary diversion after cystectomy for bladder cancer: implications for cancer control and patterns of disease recurrence. J Urol. 2003;169(1):177-81.

16. Kessler TM, Burkhard FC, Perimenis P, Danuser H, Thalmann GN, Hochreiter WW, et al. Attempted nerve sparing surgery and age have a significant effect on urinary continence and erectile function after radical cystoprostatectomy and ileal orthotopic bladder substitution. J Urol. 2004;172(4 Pt 1):1323-7.

17. Mertens LS, Meijer RP, de Vries RR, Nieuwenhuijzen JA, van der Poel HG, Bex A, et al. Prostate sparing cystectomy for bladder cancer: 20-year single center experience. J Urol. 2014;191(5):1250-5. Epub 2013/11/30.

18. Chang SS, Cole E, Cookson MS, Peterson M, Smith JA, Jr. Preservation of the anterior vaginal wall during female radical cystectomy with orthotopic urinary diversion: technique and results. J Urol. 2002;168(4 Pt 1):1442-5.

19. Mills RD, Studer UE. Metabolic consequences of continent urinary diversion. J Urol. 1999;161(4):1057-66. Epub 1999/03/19.

20. Studer UE, Hautmann RE, Hohenfellner M, Mills RD, Okada Y, Rowland RG, et al. Indications for continent diversion after cystectomy and factors affecting long-term results. Urol Oncol. 1998;4(45):172-82. 
21. McDermott WV, Jr. Diversion of urine to the intestines as a factor in ammoniagenic coma. N Engl J Med. 1957;256(10):460-2. Epub 1957/03/07.

22. Sogni F, Brausi M, Frea B, Martinengo C, Faggiano F, Tizzani A, et al. Morbidity and quality of life in elderly patients receiving ileal conduit or orthotopic neobladder after radical cystectomy for invasive bladder cancer. Urology. 2008;71(5):919-23.

23. Santucci RA, Park $\mathrm{CH}$, Mayo ME, Lange PH. Continence and urodynamic parameters of continent urinary reservoirs: comparison of gastric, ileal, ileocolic, right colon, and sigmoid segments. Urology. 1999;54(2):252-7. Epub 1999/08/12.

24. Richie JP, Skinner DG, Waisman J. The effect of reflux on the development of pyelonephritis in urinary diversion: an experimental study. J Surg Res. 1974;16(3):256-61. Epub 1974/03/01.

25. Mansson W, Colleen S, Mardh PA. The microbial flora of the continent cecal urinary reservoir, its stoma and the peristomal skin. J Urol. 1986;135(2):247-50. Epub 1986/02/01.

26. Gotoh M, Yoshikawa Y, Sahashi M, Ono Y, Ohshima S, Kinukawa T, et al. Urodynamic study of storage and evacuation of urine in patients with a urethral Kock pouch. J Urol. 1995;154(5):1850-3. Epub 1995/11/01.

27. Waidelich R, Rink F, Kriegmair M, Tatsch K, Schmeller N. A study of reflux in patients with an ileal orthotopic bladder. Br J Urol. 1998;81(2):241-6.

28. Stein JP, Freeman JA, Esrig D, Elmajian DA, Tarter TH, Skinner EC, et al. Complications of the afferent antireflux valve mechanism in the Kock ileal reservoir. J Urol. 1996;155(5):1579-84. Epub 1996/05/01.

29. Stein JP, Dunn MD, Quek ML, Miranda G, Skinner DG. The orthotopic T pouch ileal neobladder: experience with 209 patients. J Urol. 2004;172(2):584-7.

30. Shaaban AA, Gaballah MA, el-Diasty TA, Ghoneim MA. Urethral controlled bladder substitution: a comparison between the intussuscepted nipple valve and the technique of Le Duc as antireflux procedures. J Urol. 1992;148(4):1156-61.

31. Shaaban AA, Abdel-Latif M, Mosbah A, Gad H, Eraky I, Ali-El-Dein B, et al. A randomized study comparing an antireflux system with a direct ureteric anastomosis in patients with orthotopic ileal neobladders. BJU Int. 2006;97(5):1057-62. Epub 2006/04/29.

32. Skinner EC, Fairey AS, Groshen S, Daneshmand S, Cai J, Miranda G, et al. Randomized Trial of Studer Pouch versus T-Pouch Orthotopic lleal Neobladder in Patients with Bladder Cancer. J Urol. 2015;194(2):433-9. Epub 2015/04/01.

33. Gakis G, Abdelhafez MF, Stenzl A. The "I-Pouch": Results of a new ileal neobladder technique. Scandinavian journal of urology. 2015(0):1-7.

34. Abol-Enein H, Ghoneim MA. Functional results of orthotopic ileal neobladder with serouslined extramural ureteral reimplantation: experience with 450 patients. J Urol. 2001;165(5):1427-32. Epub 2001/05/09.

35. Studer UE, Burkhard FC, Schumacher M, Kessler TM, Thoeny H, Fleischmann A, et al. Twenty years experience with an ileal orthotopic low pressure bladder substitute--lessons to be learned. J Urol. 2006;176(1):161-6.

36. Hautmann RE, Egghart G, Frohneberg D, Miller K. The ileal neobladder. J Urol. 1988;139(1):39-42.

37. Koie T, Hatakeyama S, Yoneyama T, Ishimura H, Yamato T, Ohyama C. Experience and functional outcome of modified ileal neobladder in 95 patients. Int J Urol. 2006;13(9):1175-9.

38. Davis NF, Burke JP, McDermott T, Flynn R, Manecksha RP, Thornhill JA. Bricker versus Wallace anastomosis: A meta-analysis of ureteroenteric stricture rates after ileal conduit urinary diversion. Can Urol Assoc J. 2015;9(5-6).

39. Studer UE, Spiegel T, Casanova GA, Springer J, Gerber E, Ackermann DK, et al. Ileal bladder substitute: antireflux nipple or afferent tubular segment? Eur Urol. 1991;20(4):315-26. Epub 1991/01/01.

40. Bachor R, Frohneberg D, Miller K, Egghart G, Hautmann R. Continence after total bladder replacement: urodynamic analysis of the ileal neobladder. Br J Urol. 1990;65(5):462-6.

41. Hautmann RE, de Petriconi R, Gottfried HW, Kleinschmidt K, Mattes R, Paiss T. The ileal neobladder: complications and functional results in 363 patients after 11 years of followup. J Urol. 1999;161(2):422-7.

42. Hautmann RE, Volkmer BG, Schumacher MC, Gschwend JE, Studer UE. Long-term results of standard procedures in urology: the ileal neobladder. World J Urol. 2006;24(3):305-14.

43. Kock NG, Nilson AE, Nilsson LO, Norlen LJ, Philipson BM. Urinary diversion via a continent ileal reservoir: clinical results in 12 patients. J Urol. 1982;128(3):469-75.

44. Pagano F, Artibani W, Ligato P, Piazza R, Garbeglio A, Passerini G. Vescica Ileale Padovana: a technique for total bladder replacement. Eur Urol. 1990;17(2):149-54. 
45. Ferriero M, Simone G, Rocchegiani A, Buscarini M, Papalia R, Alcini A, et al. Early and late urodynamic assessment of Padua ileal bladder. Urology. 2009;73(6):1357-62. Epub 2009/04/21.

46. Zhang Z, Qi H, Zhou R, Jin X. Early and late urodynamic assessment of the orthotopic Nshaped neobladder. Oncol Lett. 2013;6(4):1053-6. Epub 2013/10/19.

47. Abol-Enein $\mathrm{H}$, Ghoneim MA. Further clinical experience with the ileal $\mathrm{W}$-neobladder and a serous-lined extramural tunnel for orthotopic substitution. $\mathrm{Br} J$ Urol. 1995;76(5):558-64. Epub 1995/11/01.

48. Pruthi RS, Nix J, McRackan D, Hickerson A, Nielsen ME, Raynor M, et al. Robotic-assisted laparoscopic intracorporeal urinary diversion. Eur Urol. 2010;57(6):1013-21. Epub 2010/01/19.

49. Jonsson MN, Adding LC, Hosseini A, Schumacher MC, Volz D, Nilsson A, et al. Robotassisted radical cystectomy with intracorporeal urinary diversion in patients with transitional cell carcinoma of the bladder. Eur Urol. 2011;60(5):1066-73.

50. Dangman BC, Lebowitz RL. Urinary tract calculi that form on surgical staples: a characteristic radiologic appearance. AJR Am J Roentgenol. 1991;157(1):115-7.

51. Ferriero M, Guaglianone S, Papalia R, Muto GL, Gallucci M, Simone G. Risk Assessment of Stone Formation in Stapled Orthotopic lleal Neobladder. J Urol. 2014;16(14):008.

52. Paparel P, Akin O, Sandhu JS, Otero JR, Serio AM, Scardino PT, et al. Recovery of urinary continence after radical prostatectomy: association with urethral length and urethral fibrosis measured by preoperative and postoperative endorectal magnetic resonance imaging. Eur Urol. 2009;55(3):62939.

53. Shah HN, Nayyar R, Rajamahanty S, Hemal AK. Prospective evaluation of unidirectional barbed suture for various indications in surgeon-controlled robotic reconstructive urologic surgery: Wake Forest University experience. Int Urol Nephrol. 2012;44(3):775-85.

54. Wilson TG, Guru K, Rosen RC, Wiklund P, Annerstedt M, Bochner BH, et al. Best practices in robot-assisted radical cystectomy and urinary reconstruction: recommendations of the Pasadena Consensus Panel. Eur Urol. 2015;67(3):363-75.

55. Bochner BH, Dalbagni G, Sjoberg DD, Silberstein J, Keren Paz GE, Donat SM, et al. Comparing Open Radical Cystectomy and Robot-assisted Laparoscopic Radical Cystectomy: A Randomized Clinical Trial. Eur Urol. 2014. Epub 2014/12/17.

56. Smith ND, Castle EP, Gonzalgo ML, Svatek RS, Weizer AZ, Montgomery JS, et al. The RAZOR (randomized open vs robotic cystectomy) trial: study design and trial update. BJU Int. 2015;115(2):198-205. Epub 2015/01/28. 
Figure 1: Schematic of different robotic intracorporeal neobladder techniques. A: Pyramid pouch. Urethro-ileal anastomosis is performed followed by detubularisation of the ileum at its anti-mesenteric border. The posterior and anterior plate is then closed with absorbable sutures and the folded edge of the neobladder is closed from lateral to medial. Uretero-ileal anastomosis is performed using the Bricker technique B: $\mathbf{U}$ shaped neobladder. The endoscopic stapler is used at the anti-mesenteric border of the ileum. Ureteroileal anastomosis is performed and the cranial end of the neobladder is closed with staples/ absorbable sutures and urethra-ileal anastomosis is performed using the Bricker technique. C1 \& C2: USC modified Studer neobladder. Isolated $44 \mathrm{~cm}$ segment of ilium is detubularised while $15 \mathrm{~cm}$ is preserved for the afferent limb. The posterior plate is closed with absorbable sutures and rotated $90^{\circ}$ counterclockwise. Urethro-ileal anastomosis is performed and the anterior suture line is closed followed by ureteroileal anastomosis using the Bricker technique. D1 \& D2: Karolinska modified Studer neobladder. Ileum is isolated in a $\mathrm{J}$ configuration and urethra-ileal anastomosis is performed. llium is detubularised and posterior plate closure is performed. The anterior wall of the neobladder is folded to close the neobladder anteriorly with absorbable sutures. Uretero-ileal anastomosis is performed at the afferent limb in a Wallace fashion. 


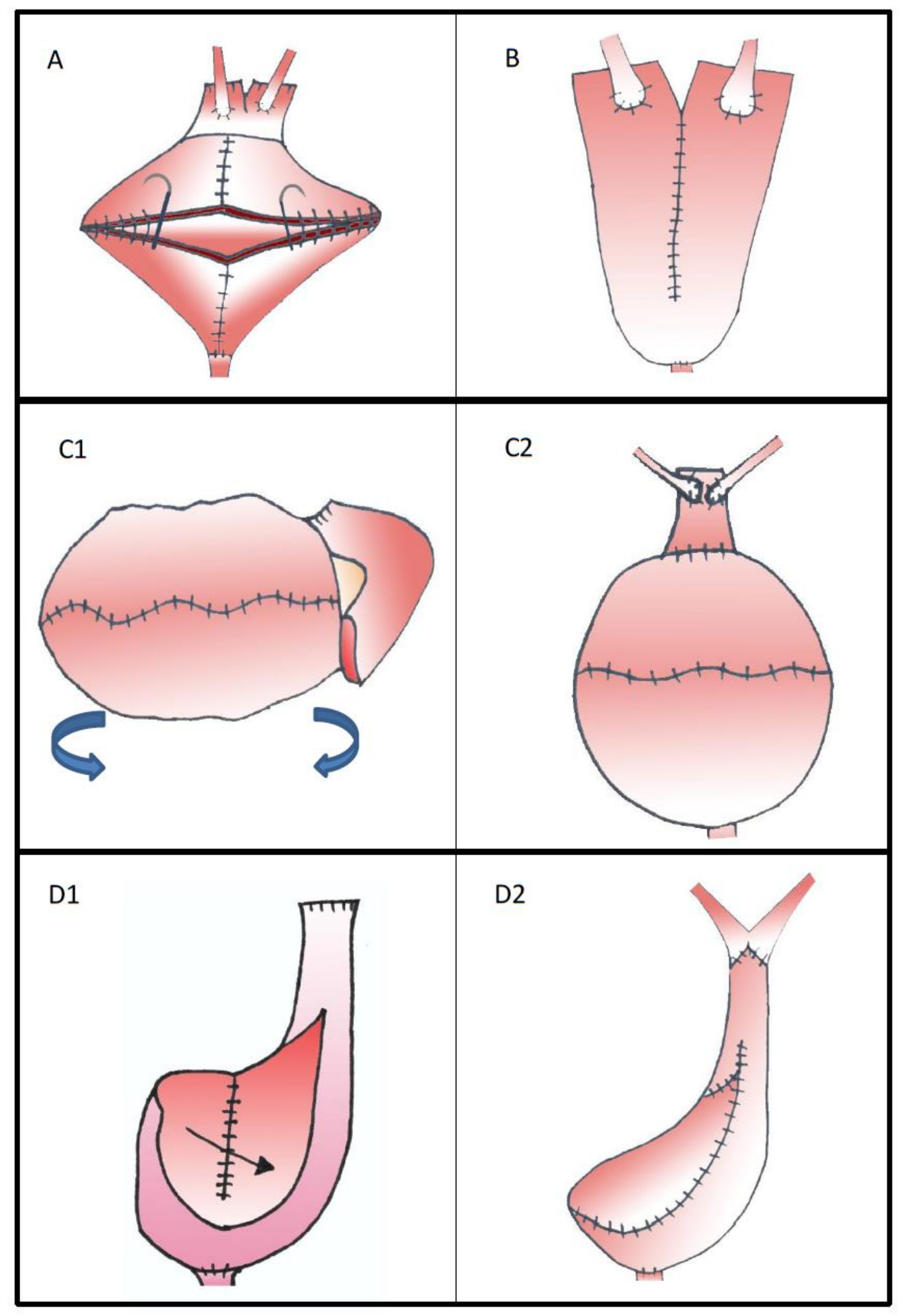


Table 1: Comparison of intestinal segments used for neobladder reconstruction

\begin{tabular}{|c|c|c|c|}
\hline $\begin{array}{l}\text { Intestinal } \\
\text { segment }\end{array}$ & Advantage & Disadvantage & $\begin{array}{l}\text { Intraluminal pressure at } \\
\text { capacity }\left(\mathrm{cm} \mathrm{H}_{2} \mathrm{O}\right)(23)\end{array}$ \\
\hline $\begin{array}{l}\text { llium/ } \\
\text { ileocaecal }\end{array}$ & $\begin{array}{l}\text { More compliant and less } \\
\text { contractile than colon and } \\
\text { stomach }\end{array}$ & $\begin{array}{l}\text { Hypokalaemic hyperchloremic metabolic } \\
\text { acidosis, fat and bile salt malabsorption, } \\
\text { diarrhoea, Vitamin B12 deficiency, bone } \\
\text { demineralisation }\end{array}$ & $\begin{array}{l}\text { llium: } 4 \pm 9 \\
\text { Ileocecal: } 10 \pm 10\end{array}$ \\
\hline Colon & $\begin{array}{l}\text { Option for patients with prior } \\
\text { pelvic radiotherapy }\end{array}$ & $\begin{array}{l}\text { Hypokalaemic hyperchloremic metabolic acidosis, } \\
\text { significant mucous production, bone } \\
\text { demineralisation, pyelonephritis, risk of } \\
\text { adenocarcinoma at anastomosis }\end{array}$ & $\begin{array}{l}\text { Colonic: } 21 \pm 24 \\
\text { Sigmoid: } 40 \pm 22\end{array}$ \\
\hline Jejunum & $\begin{array}{l}\text { Option for patients who had } \\
\text { pelvic radiotherapy }\end{array}$ & $\begin{array}{l}\text { Hyperkalaemic hypochloremic metabolic acidosis, } \\
\text { nausea/ vomiting }\end{array}$ & NA \\
\hline Stomach & $\begin{array}{l}\text { Option for patients who had } \\
\text { pelvic radiotherapy, } \\
\text { beneficial for patients with } \\
\text { renal and/or liver dysfunction, } \\
\text { low mucous production }\end{array}$ & $\begin{array}{l}\text { Hypokalaemic hypochloremic metabolic alkalosis, } \\
\text { haematuria- dysuria syndrome }\end{array}$ & $23 \pm 15$ \\
\hline
\end{tabular}


Table 2: Comparison between anti-reflux and freely refluxing urethro-ileal anastomosis

\begin{tabular}{|c|c|c|c|c|c|c|}
\hline Technique & Author & Disadvantage & $\begin{array}{l}\text { Number } \\
\text { of } \\
\text { patients }\end{array}$ & $\begin{array}{l}\text { Median } \\
\text { follow-up } \\
\text { in months } \\
\text { (range) }\end{array}$ & Stricture rate & $\begin{array}{l}\text { Reflux } \\
\text { rate }\end{array}$ \\
\hline \multicolumn{7}{|l|}{ Anti-reflux techniques } \\
\hline Studer isoperistaltic limb & $\begin{array}{l}\text { Studer et al. } \\
\text { (35) }\end{array}$ & $\begin{array}{l}\text { Extra } 20 \mathrm{~cm} \text { of ilium } \\
\text { used for isoperistaltic } \\
\text { limb }\end{array}$ & 482 & $32(0.4-208)$ & $2.7 \%$ & $\begin{array}{l}\text { Not } \\
\text { reported }\end{array}$ \\
\hline $\begin{array}{l}\text { Le Duc technique- Embedded ureter in } \\
\text { mucosal sulcus }\end{array}$ & $\begin{array}{l}\text { Shaaban et al. } \\
\text { (30) }\end{array}$ & High stenosis rate & 40 & 18 & $1.5-29 \%$ & $2.5 \%$ \\
\hline $\begin{array}{l}\text { Kock ileal reservoir- Intussuscepted } \\
\text { nipple valve }\end{array}$ & Stein et al. (28) & $\begin{array}{l}\text { Desusception, high } \\
\text { stenosis rate, stone } \\
\text { formation }\end{array}$ & 802 & $\begin{array}{l}73.2(0- \\
127.2)\end{array}$ & $\begin{array}{l}10.4 \%-\text { afferent anti-reflux } \\
\text { nipple valve } \\
2.2 \% \text { uretero-ileal anastomosis }\end{array}$ & $\begin{array}{l}\text { Not } \\
\text { reported }\end{array}$ \\
\hline T pouch- afferent flap valve & Stein et al. (29) & $\begin{array}{l}\text { Stenosis rate, more } \\
\text { complex } \\
\text { reconstruction }\end{array}$ & 209 & $33(0-69)$ & $10 \%$ & $10 \%$ \\
\hline $\begin{array}{l}\text { Abol-Enein \& Ghoneim- Extramural } \\
\text { serous-lined tunnel (Bricker } \\
\text { anastomosis) }\end{array}$ & $\begin{array}{l}\text { Abol-Enein et al. } \\
\text { (34) }\end{array}$ & $\begin{array}{l}\text { Not suitable for } \\
\text { dilated/ pathological } \\
\text { ureters }\end{array}$ & 450 & $35(8-88)$ & $3.8 \%$ & $3 \%$ \\
\hline $\begin{array}{l}\text { I pouch- Sub-serosal tunnel (Wallace } \\
\text { anastomosis) }\end{array}$ & Gakis et al (33) & $\begin{array}{l}\text { May not be suitable } \\
\text { for dilated/ } \\
\text { pathological ureters }\end{array}$ & 97 & $41(3-107)$ & $2.1 \%$ & $1 \%$ \\
\hline
\end{tabular}




\begin{tabular}{|l|l|l|l|l|l|}
\hline $\begin{array}{l}\text { Bricker technique- Separate ureteric- } \\
\text { ilium anastomosis using interrupted } \\
\text { sutures }\end{array}$ & Davis et al. (38) & & 212 & $27 \pm 5$ & 5.8 \\
\hline $\begin{array}{l}\text { Wallace technique- Conjoined ureteric- } \\
\text { ilium anastomosis using continuous } \\
\text { sutures }\end{array}$ & Davis et al. (38) & & 258 & $26 \pm 5$ & 3.9 \\
\hline
\end{tabular}


Table 3: Comparison between commonly performed open neobladder techniques

\begin{tabular}{|c|c|c|c|c|c|c|c|}
\hline \multirow[t]{2}{*}{ Technique } & \multirow[t]{2}{*}{ Author } & \multirow{2}{*}{$\begin{array}{l}\text { Length of } \\
\text { bowel }(\mathrm{cm})\end{array}$} & \multirow{2}{*}{$\begin{array}{l}\text { Number of } \\
\text { patients }\end{array}$} & \multirow{2}{*}{$\begin{array}{l}\text { Median follow- } \\
\text { up in months } \\
\text { (range) }\end{array}$} & \multicolumn{2}{|c|}{ Continence } & \multirow{2}{*}{$\begin{array}{l}\text { Intermittent } \\
\text { catheterisation }\end{array}$} \\
\hline & & & & & Day & Night & \\
\hline $\begin{array}{l}\text { Studer neobladder- afferent limb } \\
\text { and 'U configuration' }\end{array}$ & Studer et al. (35) & 55 & 482 & $32(0.4-208)$ & $92.0 \%$ & $79 \%$ & $7.0 \%$ \\
\hline $\begin{array}{l}\text { Hautmann neobladder- 'W } \\
\text { configuration' }\end{array}$ & $\begin{array}{l}\text { Hautmann et al. } \\
(41)\end{array}$ & 70 & 383 & $\begin{array}{c}\text { Mean: } 57(10- \\
137)\end{array}$ & $95.9 \%$ & $95.0 \%$ & $3.9 \%$ \\
\hline $\begin{array}{l}\text { T pouch- T shape with tapered } \\
\text { afferent ileal segment }\end{array}$ & Stein et al. (29) & 60 & 209 & $33(0-69)$ & $87.0 \%$ & $72.0 \%$ & $25.0 \%$ \\
\hline $\begin{array}{l}\text { Padua neobladder- Reverse 'S } \\
\text { configuration' }\end{array}$ & $\begin{array}{l}\text { Ferriero et al. } \\
\text { (45) }\end{array}$ & 40 & 46 & 48 & $90.0 \%$ & $60.0 \%$ & $2.2 \%$ \\
\hline $\begin{array}{l}\text { Abol-Enein \& Ghoneim } \\
\text { neobladder- 'W' configuration }\end{array}$ & $\begin{array}{l}\text { Abol-Enein et al. } \\
\text { (34) }\end{array}$ & 40 & 450 & $35(8-88)$ & $93.3 \%$ & $80.0 \%$ & $2.0 \%$ \\
\hline
\end{tabular}


Table 4: Comparison between intracorporeal robotic neobladder techniques. M: male, F: female

\begin{tabular}{|c|c|c|c|c|c|c|c|c|c|c|}
\hline \multirow[t]{2}{*}{ Study } & \multirow{2}{*}{$\begin{array}{l}\text { Length } \\
\text { of ilium } \\
\text { (cm) }\end{array}$} & \multirow{2}{*}{$\begin{array}{l}\text { Bricker/ } \\
\text { Wallace }\end{array}$} & \multirow[t]{2}{*}{ Shape } & \multirow{2}{*}{$\begin{array}{l}\text { Detubula } \\
\text { rised } \\
\text { ilium }\end{array}$} & \multirow{2}{*}{$\begin{array}{l}\text { Afferent } \\
\text { limb }\end{array}$} & \multirow{2}{*}{$\begin{array}{l}\text { Stapler } \\
\text { use }\end{array}$} & \multirow[t]{2}{*}{ Technique } & \multirow{2}{*}{$\begin{array}{c}\text { Median } \\
\text { operating } \\
\text { time, mins }\end{array}$} & \multicolumn{2}{|c|}{12 months continence } \\
\hline & & & & & & & & & Day & Night \\
\hline $\begin{array}{l}\text { Jonsson et } \\
\text { al. (49) }\end{array}$ & 50 & Wallace & Studer & $\mathrm{X}$ & $X$ & & $\begin{array}{l}\text { Urethro-ieal anastamosis } \\
\text { then NB reconstruction }\end{array}$ & 420 & $97 \%$ & $83 \%$ \\
\hline $\begin{array}{l}\text { Goh et al. } \\
\text { (6) }\end{array}$ & 60 & Bicker & Studer & $X$ & $X$ & & $\begin{array}{l}\text { NB reconstruction then } \\
\text { urethra-ileal anastamosis }\end{array}$ & 450 & $\begin{array}{c}75 \% \\
\text { (3 months) }\end{array}$ & \\
\hline $\begin{array}{l}\text { Pruthi et } \\
\text { al. (48) }\end{array}$ & $\begin{array}{c}\text { Not } \\
\text { known }\end{array}$ & Bricker & U shape & $\mathrm{X}$ & & $\mathrm{X}$ & $\begin{array}{l}\text { NB reconstruction then } \\
\text { urethra-ileal anastamosis }\end{array}$ & 318 & & \\
\hline $\begin{array}{l}\text { Tan et al. } \\
\text { (7) }\end{array}$ & 50 & Bricker & Pyramid & $\mathrm{X}$ & & & $\begin{array}{l}\text { Urethro-ieal anastamosis } \\
\text { then NB reconstruction }\end{array}$ & 330 & $\begin{array}{c}95 \% \\
\text { (6 months) }\end{array}$ & $\begin{array}{c}70 \% \\
\text { (6 months) }\end{array}$ \\
\hline
\end{tabular}

